\title{
The Future of Psychopharmacological Enhancements: Expectations and Policies
}

\author{
Maartje Schermer • Ineke Bolt • \\ Reinoud de Jongh • Berend Olivier
}

Received: 19 September 2008 / Accepted: 15 January 2009/Published online: 11 February 2009

(C) The Author(s) 2009. This article is published with open access at Springerlink.com

\begin{abstract}
The hopes and fears expressed in the debate on human enhancement are not always based on a realistic assessment of the expected possibilities. Discussions about extreme scenarios may at times obscure the ethical and policy issues that are relevant today. This paper aims to contribute to an adequate and ethically sound societal response to actual current developments. After a brief outline of the ethical debate concerning neuro-enhancement, it describes the current state of the art in psychopharmacological science and current uses of psychopharmacological enhancement, as well as the prospects for the near future. It then identifies ethical issues regarding psychopharmacological enhancements that require attention from policymakers, both on the professional and on the governmental level. These
\end{abstract}

M. Schermer $(\bowtie) \cdot$ I. Bolt

Medical Ethics and Philosophy of Medicine, ErasmusMC, P.O. Box 2040, Rotterdam, CA 3000, The Netherlands e-mail: m.schermer@erasmusmc.nl

I. Bolt

Ethics Institute, Utrecht University,

P.O. Box 80103, Utrecht, TC 3508, The Netherlands

R. de Jongh

Institute of Psychology, Erasmus University,

P.O. Box 1738, Rotterdam, DR 3000, The Netherlands

B. Olivier

Pharmaceutical Sciences, Utrecht University,

P.O. Box 80082, Utrecht, TB 3508, The Netherlands concern enhancement research, the gradual expansion of medical categories, off-label prescription and responsibility of doctors, and accessibility of enhancers on the Internet. It is concluded that further discussion on the advantages and drawbacks of enhancers on a collective social level is still needed.

Keywords Psychopharmacology Enhancement . Policy

\section{Introduction}

Over the past decade, possibilities for human enhancement have been hotly debated in bioethics, especially with regard to genetics and new and emerging biotechnologies. More recently, this discussion also turned to the possibilities for enhancing mental functioning of people. The enhancement of mood and cognition, especially by means of psychoactive drugs, has raised significant controversy. Some see a great enhanced future ahead, while others dread a decline of important human values if neuro-enhancement were possible. These hopes and fears are not always based on a realistic view of what is and might be possible with regard to neuro-enhancement and in our view this sometimes interferes with formulating adequate policies and regulations alongside the development of new enhancement technologies.

In this paper we will first give a brief outline of the ethical debate concerning neuro-enhancement, and 
then describe the current state of affairs and the prospects that we consider to be realistic. Departing from this assessment, we will identify the present and emerging ethical issues regarding psychopharmacological enhancements that require attention from policymakers, both on the professional and on the governmental level. Our aim is to contribute to an adequate and ethically sound societal response to these developments.

\section{Overview of the Debate}

The ethical debate on psychopharmacological enhancement is taking place at the intersection of two related fields. First, it is part of the emerging field of neuroethics, which has been booming since the term was coined in 2002 [1-4]. Second, it is part of the wider debate on human enhancement, which has been going on since about the late 1980's [5-8] and is concerned with all kinds of human enhancementsfrom cosmetic surgery to genetic modification of our offspring.

The specific issue of enhancing mental functions through medicines has been discussed in a number of publications. Before the discussion was even framed in terms of 'enhancement', two drugs especially raised social concern and ethical discussion: fluoxetine $\left(\right.$ Prozac $^{\circledR}$ ) and methylphenidate (Ritalin ${ }^{\circledR}$ ). These are existing drugs that are prescribed for recognized diseases - clinical depression and ADHD respectively - but that are also used for a wider range of purposes than the treatment of these diseases. Prozac $^{\circledR}$ was popular in the 1990's to improve personality traits and to diminish feelings of sadness or alienation that, according to some, simply belong to normal life $[9,10]$. Ritalin ${ }^{\circledR}$ was allegedly being used to subdue bouncy children as well as to help students cram for exams [11]. The main issues in this debate circled around medicalization, normalization and social adaptation on the one hand, versus diversity and authenticity on the other.

With the advance of new technologies, especially drugs that promise to enhance cognitive capacities, a new phase in the neuro-enhancement debate has started. The discussion has become directed not at the use of existing drugs, but more and more at the expectations of the use of future drugs, which are yet to be developed [12-14]. The ethical issues that are raised here concern, among others, safety and risks; justice and equal opportunity; coercion and social pressure; and identity and authenticity.

The promise of new wonder drugs, or other technologies that might enhance cognitive and other mental functions such as DBS or TMS, has invoked roughly two types of reaction: utopian and dystopian [15]. On the one hand, there are those who argue in favor of enhancing ourselves. They are opposed to bans on such new technologies and see great prospects for the future of humanity; some even promote our transformation into posthuman beings [8, $16,17]$. On the other hand, there are the bioconservatives who oppose enhancement technologies and fear that these will corrupt and degrade us and rob us of what is 'naturally human' $[6,18,19]$.

A significant part of the debate on human enhancement, we assert, suffers from inflated expectations and technology hype. This part of the debate focuses on Enhancements with a capital E: enhancements that go beyond what we currently understand as the normal or naturally human. Giving people infrared vision, engineering them with perfect pitch, doubling or tripling their IQ, overcoming our need for sleep, or achieving immortality are all unlikely prospects for the near future [20]. While speculating about our future powers and future scenarios is exciting and may be a very useful way to explore emerging ethical issues related to science and technology [23], the high expectations that are raised also serve certain interests. To attract attention, allies and large-scale investment potential benefits are hyped up and risks and costs are played down. Inevitably, however, this will provoke a reaction and fuel and enflame widespread concerns and anxieties about risk [21].

In the same line, Nordmann warns against what he calls speculative ethics [22]. Speculative ethics invites us to discuss the pros and cons of emerging technologies as if such technologies were upon us already. One should be cautious that ethical questions that already present themselves with regard to the current state of technology are not obscured. There are numerous important ethical and policy questions to be asked with regard to less spectacular forms of enhancement - enhancements with a small e-that are possible already, or will be in the near future. Breast implants, growth hormone for short children, improving alertness or adjusting to sleep depletion with 
psychopharmacology, are all examples of this. We agree with Nordmann that we should stay 'close on the heels' of new emerging technologies and the ethical issues that they present.

In this paper we will therefore focus on what we take to be a realistic perspective and assess the present and emerging ethical issues regarding psychopharmacological enhancements for the near future. With psychopharmacological enhancements we will mean pharmacological interventions that are intended to improve certain mental functions and that go beyond currently accepted medical indications.

\section{Psychopharmacology and Enhancement: State of the Art}

Presently, the main focus of attention in the discussion on psychopharmacology and enhancement seems to be on cognitive enhancement. This includes a large variety of functions such as concentration, alertness, working memory, long-term memory et cetera. Enhancing effects on cognition can only be shown on the level of such distinct functions. 'Intelligence' is a trait that many would like to see enhanced, but it is a far too complex and multi-faceted trait to be enhanced by one single intervention.

Enhancement of other than cognitive functions currently receives less attention, both in the ethical discussion as in neuroscientific research. SSRI's, like the drug fluoxetine (Prozac ${ }^{\circledR}$ ) that once initiated the hype on mood enhancement, have hardly any proven effects in healthy volunteers. It certainly does not elevate a normal mood to a happy one, although it does appear to reduce negative affect (sadness, anxiety) and promote affiliative behavior [24].

The psychopharmacological substances that are potential cognitive enhancers can be distinguished into two categories: drugs that are already on the market for specific indications, like Alzheimer's disease, ADHD or narcolepsy, and (classes of) drugs that are being developed. The first group includes donepezil, modafinil, guanfacine, methylphenidate and various dopamine agonists. The second group consists of substances in the research stage and is aimed at the AMPA receptor, the NMDA receptor or CREB (cAMP response binding protein).

In a systematic review of the proven effects of these drugs in healthy subjects we concluded that they do have some cognitive enhancing effects, specifically on working memory, executive functioning (spatial planning ability), sustained attention and episodic memory [24].

Interestingly, one of the most frequently discussed cognition enhancers, modafinil, appears to be most effective during suboptimal performance, due to either sleep deprivation, or 'lower natural abilities'. So far, no studies have found any positive effects of the drug in subjects already performing at optimal levels. Moreover, the effects that have been found are modest. In one study, the effects on alertness and performance during sleep deprivation are comparable to those of $600 \mathrm{mg}$ of caffeine (six cups of coffee) and modafinil improves performance in only 6 out of 29 cognitive tests $[25,26]$.

Another much debated drug is methylphenidate $\left(\right.$ Ritalin $\left.^{\circledR}\right)$. Since this is a psychostimulant it does keep you awake and alert. However, it does not appear to have effect on concentration or sustained attention in healthy volunteers [27]. Moreover, while methylphenidate enhances executive function on novel tasks, it impairs previously established performance.

The fact that the enhancing effects of the present generation of psychopharmacological substances are modest does not, of course, imply that future drugs will not have more forceful effects. There appear to be, however, a number of underlying mechanisms that - if they apply to cognitive enhancement in general-may temper enthusiasm as well as worries about the non-medical or commercial use of these psychoactive agents. Common phenomena that arise across different neurotransmitter systems and with different pharmacological agents suggest that we may be able to formulate general principles of a inverted $U$ shape response and trade-offs. First, as cognition-enhancing drugs can simultaneously exert both linear and quadratic (U-shaped) effects, doses most effective in facilitating one function could at the same time exert null or even detrimental effects on other cognitive domains. This means that they will likely not improve over all performance, but enhance some functions while impairing others.

Second, studies on dopamine augmentation provide some support for a baseline dependency: individuals with a 'low memory span' benefit from administration of dopamine agonists, whereas 'high span subjects' are 'overdosed' and show a deteriora- 
tion of performance. So, naturally low performing subjects may benefit more than those who perform well already.

Finally, there is evidence that a number of tradeoffs are likely to occur: enhancement of long-term memory could impair working memory; enhancing the consolidation of long-term memory might disrupt the ability of new information to modify those memories and thus to respond adequately to a changed environment; and increases of cognitive stability (which benefits working memory maintenance) come at the cost of a decreased capacity to flexibly alter behavior.

With regard to future targets for enhancing cognition, the development of the ampakines appears to be furthest along. Even there, however, there has been a paucity of studies on human volunteers. It remains to be seen whether these drugs really do prove to be any more effective than the currently available enhancers, and if they do not run into the same 'practical problems' and tradeoffs discussed above. Though sudden scientific breakthroughs can never be excluded, for the near future it seems likely that only modest enhancement of mental function will be attainable.

\section{Current and Future Uses of Cognitive Enhancers}

In this paper we do not want to focus on hypothetical cases - what if we suddenly had perfectly effective and safe enhancers? - but try to assess the current and near future developments regarding psychopharmacological enhancement. We see a number of routes along which psychopharmacological enhancement will probably develop, influenced by various social, institutional and psychological factors.

First, development of new drugs will most likely take place not under the banner of 'enhancement' but as normal medical or neuroscientific research aimed at treating diseases such as Alzheimer, the cognitive impairments of schizophrenia, ADHD, autism-spectrum disorders et cetera. As Juengst and collegues formulate it "most interventions that might be used for the enhancement of the healthy will be developed under the aegis of perfectly legitimate medical concerns to treat and prevent traditionally defined disease, disability, and suffering in the sick [...] enhancement interventions will appear, fait accompli, as 'off-label' applications of existing medical tools"
[28]. ${ }^{1}$ Given the current regulations, purposeful development of drugs aimed at the enhancement of normal functioning is not opportune for pharmaceutical companies. Nick Bostrom therefore points out the need for changing existing regulations: "The disease centered framework impedes the development of safe and effective enhancing medicines" [30]. Though we believe this is an important discussion that should be conducted, it is not to be expected that existing regulative frameworks will change radically in the near future and for the time being existing regulations will guide the developments.

Second, disease categories in the field of mental health are likely to expand and come to include states, behavior patterns, personality traits and the like that are at present not recognized as disorders. Since the first edition of the American Psychiatric Association's Diagnostic and Statistical Manual was published in 1952, more than four hundred new categories of mental illness have been conceived [31]. In part, these expanded or new disease categories can be understood as the product of 'disease mongering': more or less conscious attempts of the pharmaceutical industry (and of scientists and physicians with similar interests) to create new diseases in order to sell more drugs [32]. This is already happening at the moment, for instance with the emergence of disorders like shiftworker's sleep disorder, age-associated memory impairment, involuntary emotional expression, or female sexual dysfunction. By labeling formerly 'normal' states as disorders or diseases, they become legitimate goals of pharmacotherapy; and by smart marketing techniques awareness is raised among both patients and doctors regarding the existence of these new disorders, as well as the possibilities for treatment.

For another part, the boundaries of existing disorders, like ADHD or autism, will be stretched and expanded without any conscious efforts of disease mongerers. When diagnostic tools become more sensitive and when symptoms are recognized more widely because of a greater awareness of disorders more people will be diagnosed as having a disorder. This can be understood as either proper diagnosis of formerly under-recognized diseases, or as forms of medicalization and normalization [33, 34]. Moreover, once the worst cases have been properly

\footnotetext{
${ }^{1}$ Off-label use is the prescription of drugs for a purpose that is not included in the drug's approved label
} 
treated, attention will naturally shift to those with fewer symptoms. The boundaries of what is considered 'normal' may thus shift. Both processes will help to expand the use of psychopharmacological substances beyond what we currently see as proper medical indications. Within this contested area it is not obvious but rather a matter of fierce dispute whether we are talking about treatment or enhancement-or perhaps, in some cases of disease mongering, even about selling illusions.

Finally, the use of cognitive - or mood enhancing drugs may expand due to increasing knowledge of the general public regarding the existence of enhancers and the easy online access to all kind of 'smart drugs'. Psychoactive medication is already being used for enhancement purposes by a number of people. The best-known example is that of students using Ritalin ${ }^{\circledR}$ or similar psychostimulant medication as a study aid, to improve attention or remain alert. In the USA 6,9 to $16,2 \%$ of college students is reported to have used psychostimulants for this purpose [35-37]. A recent study in the Netherlands showed that $2,4 \%$ of the students between 12-18 years have used medication for non-medical purposes in the past year. Half of them $(1,2 \%)$ used Ritalin ${ }^{\circledR}$; it is not clear whether this was used to improve concentration and attention in study, or for partying and the 'high' effect of Ritalin ${ }^{\circledR}$ [38]. In Belgium, a recent poll among 1,500 university students showed that 3\% used psychostimulants during their exam periods; another poll indicated that this might even be up to $20 \%$ [39]. A recent Internet poll conducted by Nature, to which 1,400 scientists from 60 different countries reacted, revealed that one in five $^{2}$ scientists uses psychoactive drugs for nonmedical purposes [40]. Of those using enhancers, $62 \%$ used methylphenidate, and $44 \%$ modafinil. The most popular reason for taking the drugs was to improve concentration. Improving focus for a specific task (admittedly difficult to distinguish from concentration) ranked a close second and counteracting jet lag ranked fourth, after 'various reasons'. 3

Attitudes about the use of psychoactive medication for enhancement purposes vary significantly.

\footnotetext{
${ }^{2}$ It must be noted that this figure is not based on a representative sample

${ }^{3}$ Some of the respondents of the three mentioned polls obtained medication by prescription while others purchased the drugs on the Internet or got them from friends or relatives.
}

Some people are enthusiastic and willing to try while others are afraid of potential risks, or consider it to be a form of cheating [41]. Attitudes may vary with a country's general attitude towards drugs. The Netherlands for example are well-known for their pharmacological Calvinism-the use of medication is much lower than in countries such as France or Spain. At the same time, attitudes towards drugs like marijuana or narcotics may be more liberal. Some population groups may have specific attitudes: according to a Dutch study many of the students using off-label medication also used other (illegal) drugs and experimented with all kinds of different substances [38]. Some of them were problematic drug-users or had psychosocial problems. The group of scientists from the Nature poll, on the other hand, apparently is well informed and consciously calculates the desired effects and possible risks. Different practices of medication use for enhancement purposes may thus exist and develop further in the future: incidental boosts for special occasions; continuous use to improve performance in high-pressure competitive surroundings; experimentation for curiosity or fun; substance abuse and automedication of mental problems. The fact that it is so easy to learn about enhancers and to purchase them on the Internet stimulates this. It is possible for some groups to use enhancing substances in a conscious and well-informed way, but the same drugs can often also be abused by less informed and more vulnerable people.

In summary, we believe that in the near future new psychoactive medication will be developed that is primarily intended for specific disorders or diseases, but that can have enhancing effects on various mental functions in healthy people as well. These effects will probably be moderate, will enhance certain functions while impeding others, and may not work equally well for everyone. The use of these psychoactive drugs is likely to expand beyond current medical indications along any of three lines:

1) Prescription use for 'under recognized' or 'newly recognized' disorders

2) Off-label prescription of medication for enhancement purposes

3) Non-prescription use of medication for enhancement purposes 


\section{Ethics \& Policies}

Starting from this scenario we will now analyze the most important ethical questions that need to be addressed by public policy, and formulate some policy advices.

Should the Government Prohibit or Promote Enhancement Research?

A first important issue is whether the development of enhancing drugs should be forbidden or on the contrary, as some philosophers argue, whether we have a moral obligation to pursue enhancement $[8$, 52].

The argument for a moral duty to enhance is often made from a utilitarian point of view: if a certain development or intervention will benefit us, both individually and as a society, it ought to be pursued. The assumption of proponents is that the development and use of enhancers will create benefits-longer, healthier, happier, better lives for more people. Harris even defines enhancements as those interventions or techniques that do benefit us in this way, which makes the duty to enhance a re-statement of a general duty of beneficence. As such, the duty to enhance is an imperfect duty: a duty to aim at a certain end. In contrast to perfect duties, imperfect duties do not spell out exactly when and how to act. While perfect duties clearly describe the acts do be done (or omitted, in case of negative duties) and the conditions under which these ought to be done, imperfect duties allow more latitude. It is typical for imperfect duties that the acts they require cannot be spelled out exactly but give persons some freedom to decide how and on what occasions to fulfill them. Therefore, an imperfect duty to enhance (i.e. a duty of beneficence) does not give us much direction or guidance. It is unclear to whom this duty applies (the government, organizations that fund research, biomedical researchers, doctors, all of us); what it implies (exactly which actions are required?); and under what conditions it applies. Finally, it remains unclear how we are supposed to prioritize the myriad ways in which we could benefit people. Why develop cognitive enhancers and not malaria drugs? Why spend money on drug development instead of education?

In order to transform this very general imperfect duty of enhancement into one or more perfect duties, a number of steps needs to be taken to specify whom the duty addresses, which concrete actions it requires and under what conditions it applies. All these steps will require additional arguments, deliberation about concrete cases informed by relevant empirical data, and weighing against other moral duties (like a duty of justice, or other ways of fulfilling a duty of beneficence). Until those steps are taken a 'duty to enhance' appears to be little more than a pro-attitude to enhancement.

A very problematic move in the discussion on the duty to enhance is the fact that enhancement is too easily equated with beneficence. The proponents of a duty to enhance either define enhancement as beneficial [8], or claim that if enhancements benefit us, it is our duty to pursue them [52]. However, by doing so they avoid the important discussion on whether various types of enhancements do indeed benefit us. In the case of psychopharmacological enhancers it is not obvious that they will, not only because we presently lack sufficient empirical evidence about effects and side-effects, but also on a more fundamental level because it is not clear what conception of a good life or a good society we ought to use to assess the effects of enhancement. From a utilitarian point of view only the net happiness of the largest number of people may count, but other views on the good life stress different aspects of well-being. For example, many people would find it problematic to use enhancers if this would affect their self-identity [53].

With regard to the individual good life the liberal solution is to let everyone have his own way (as long as it does not cause serious harm to others). With regard to the good society, however, the question is more complex and requires, at least, more public discussion. A 'wake enhancing' substance like modafinil could have important social effects, e.g. on our working schedules and on the 24/7 economy. It is not obvious that this will be an overall benefit for society (or individuals) [42].

Another aspect is that of justice. Especially from a perspective of global justice it is not obvious that developing cognitive enhancers should have priority over, say, developing new anti-malaria drugs. A lot of lives could be saved and health could be much improved for many people by developing and distributing medication for old-fashioned treatment purposes, so it is not clear at all that investing money, time and expertise in developing cognitive enhancers 
would make more people better off. ${ }^{4}$ Even if it would increase net happiness in the world, the question of distributive justice could still be held against this utilitarian point of view.

For these reasons we believe it is too quick to claim that the development of psychopharmacological enhancers is a moral obligation, or that it should have any special priority over the development of other drugs.

Although we do not argue for any special priority for research on enhancing drugs, we see no reason why such research should be categorically prohibited. Freedom of research is an important good and one must have serious reasons to prohibit research. Enhancement might have undesirable societal effects in the long run, like unjust inequalities or pressure to use them, but we believe these should give rise to regulation and careful application, not to a general prohibition of research ${ }^{5}$. A more practical argument is that the development of enhancing drugs is often the spin-off of medical research and thus difficult to prohibit altogether. It is often impossible to tell in advance what the effects and applications of new findings will be. Moreover, if enhancing drugs are prescribed off label or used without prescription, it is useful to know about their effects and side effects in healthy subjects as well. If we are willing to discuss the option of allowing some drugs on the market for enhancement purposes, we must have sufficient knowledge about them. Testing the effectiveness and side-effects of enhancing drugs even appears to be indispensable, because it would provide important facts necessary for further decision making about the regulation of such drugs [54, 55]. The important question is therefore not if research ought to be allowed, but what moral framework ought to be used to regulate research with enhancing substances in

\footnotetext{
${ }^{4}$ Sometimes it is claimed that if we had effective cognitive enhancers, this would enable our scientists to be smarter and to work harder and come up with new technologies and other findings (like a cure for malaria) that would benefit us all. Enhance our scientists, and they will create technology to improve the lives of the rest of us. This argument appears to be overly optimistic about the powers of science and technology, and ignores the fact that most problems of (global) injustice and inequality have nothing to do with a lack of technological power but rather with politics, institutions and governance.

${ }^{5}$ Most technological advances bring risks or adverse effects with them, but this is not generally seen as a reason to prohibit technological development altogether.
}

human subjects; whether research should be restricted to those aiming at improving medical knowledge and therapies or including purposes of enhancement [55].

For now this discussion renders two important conclusions for policymaking. First, that it is neither ethically justified, nor practical, to prohibit the research and development of enhancing drugs; on the other hand, it is not yet clear that there is a moral obligation to promote such development either, e.g. by publicly funded research. More work is needed to specify the imperfect duty of beneficence, in order to render perfect duties concerning enhancementresearch and development. Second, the ethics of research into potentially enhancing psychopharmaceuticals deserves separate attention.

\section{How to Evaluate the Expansion of Medical Categories?}

The expansion of existing medical categories and the emergence of new medical categories promoted by pharmaceutical companies are processes that require a critical evaluation. Both processes are examples of medicalization: social processes in which more and more aspects of daily life come to be seen in medical terms, and problems come to be understood in a medical framework. This also implies an increase in medical interventions. Medicalization can be a moral good: many people who experience real problems may be helped by new therapies or by the mere recognition of their problems. There are, however, also some morally problematic aspects to medicalization.

First, the harm-benefit ratio of medication deserves constant attention. While the risks and side effects of medication are acceptable if they cure disease or improve the quality of life of people, these same risks and side effects may become unacceptable when benefits are small. The smaller the benefit that is created by pharmacological intervention, the more serious the possible risks, and the lack of information regarding long-term effects, should be taken. When drugs that have been tested and admitted for serious diseases and complaints, come to be used more and more by those who are less seriously afflicted, the risks-benefit ratio that used to be acceptable in the serious cases, may shift to unacceptable. This is still insufficiently recognized. For example, large numbers of people have been prescribed SSRI's for mild 
depressive complaints, while their effectiveness has only been (contestably) proven for very serious clinical depression $[43,56]$. According to a study of the Health Committee of the British Parliament in $2005,95 \%$ of antidepressant users are exposed to the drugs' risks and side-effects without clear evidence that the drugs benefit them [43]. So, physicians ought to make their own risk-benefit assessments for individual patients, keeping in mind this shift in risk-benefit ratio. They ought to consider the seriousness of the patient's condition and his degree of suffering. Such consideration also ought to be included in professional guidelines regarding the use of psychopharmaceuticals. However, as we will discuss later on, the influence of pharmaceutical industries and lack of reliable scientific data may hinder objective assessment and prescription practices.

A second problem of medicalization is the focus on medication or other medical interventions as the solution to complex problems. Such a focus leaves less room for alternative approaches like psychotherapy, lifestyle changes or educational or pedagogical measures that may have less side-effects than medication, or may be more effective ${ }^{6}$.

Third, an important related issue is that social factors contributing to problems are downplayed in comparison to individual biological and psychological factors. With adult ADHD, for example, the increased pressure to perform and to keep up the pace of our hectic society is not really recognized as part of the problem. The problems that patients encounter are individualized instead of socialized. ${ }^{7}$ Increasing performance pressure in an increasingly complex society leads to growing numbers of people who cannot keep

\footnotetext{
${ }^{6}$ Examples: people with symptoms of ADHD may be helped by learning to use schedules and reminders; or by regulating the amount of external stimuli. People who are anxious and shy may benefit from cognitive psychotherapy or social skills training. Shift workers may benefit from a less strenuous schedule with more time to recuperate.

${ }^{7}$ In the Netherlands, there is currently an increase in the number of young adults on a special social benefit scheme for young people who are unable to work because of medical reasons. This increase is due to the increasing numbers of young adults that are diagnosed with ADHD and related disorders like ADD or PDD-NOS. Instead of labelling these young people as abnormal and excluding them from participation in society, one might also improve and adapt working conditions for them.
}

up the pace and cannot live up to the high expectations. Likewise, the current focus on happiness as the ultimate goal in life, alongside the claims that happiness can be 'made' and that everyone is responsible for their own happiness, makes more and more people feel they fail [43].

Finally, especially in cases of disease mongering medicalization works by emphasising and magnifying existing problems, or even by stimulating feelings of insufficiency, insecurity, unhappiness or underperformance in people who did not feel that way before. In brief: people are made to feel miserable first, in order to help relief this misery afterwards by offering a medical label and accompanying treatment. Advertisements and other marketing instruments are employed to 'sell sickness'. People are influenced into believing they have a problem that they did not realize they had before. Such practices should be understood as a violation of the principle of nonmaleficence. It would indeed be more honest, and probably do less harm, if medication to enhance certain traits would be clearly named as such, and not sold under the guise of 'treatment'. As Bostrom rightly remarks, however, current regulatory frameworks make this difficult [30].

The gradual expansion of medical categories is a process that professionals and professional organizations, as well as patient and consumer organizations, should be aware of. They should learn to recognize the mechanisms that are at work in expanding disease categories and of their own role in these processesdoctors still hold an important power in defining what disease is. The risks and negative effects of drawing disease boundaries too narrow (underdiagnosis and undertreatment) have to be weighed against the risks of drawing them too wide (over treatment, stigmatization). This should have a place in professional training and education programs. Professional organizations ought to stimulate awareness and discussion among their members, for example by publications in their journals, and organization of workshops and symposia ${ }^{8}$.

The problem of influence of the drug companies on research, medical guidelines and medication use is very complex and does not have one single easy

\footnotetext{
${ }^{8}$ A good example is the Dutch Association for General Practitioners, which recently organised a masterclass with Iona Heath to discuss disease mongering with Dutch GPs. The discussion was published in a Dutch medical journal [60].
} 
solution. Only a combination of actions and regulations will be able to improve the current situation. We believe that the influence of the pharmaceutical industry on physicians and patient organizations should be strictly regulated, and awareness should be raised, e.g. through initiatives such as No Free Lunch (UK and USA) and Healthy Skepticism (Australia, The Netherlands). Direct-to-consumer advertising of medication should remain prohibited as it currently is in Europe. Major biomedical journals have requirements for manuscripts such as statements of authors accepting responsibility for the conduct of the study, that they had access to data and whether the authors controlled the decision to publish [61]. It seems these requirements are not sufficient to avoid the phenomenon of ghostwriting and ghostmanagement: pharmaceutical companies that influence and control the research, analysis, writing and publication of articles [62]. Moffatt and Elliott for example propose a few measures to combat ghostwriting practice, such as the installment of a task force whose task is to track cases of ghostwriting and to sanction authors as well as to inform the public about ghostwritten papers [63]. There are no easy solutions to avoid such phenomena but at the least awareness of all parties involved (investigators, universities, editors etc) of the mechanisms of company influence may help create adequate measures.

May Doctors Prescribe Off-Label for Enhancement Purposes?

Before a drug can be marketed, a registration authority (the FDA in the USA, the EMEA in Europe) ensures itself of the safety and effectiveness of the pharmaceutical company's product. Safety and effectiveness are determined in light of the specific purpose of the product. Approval of a product implies approval of the label for that product. That label should include detailed information about the product, approved indication dosage, method of administration, and use in specific populations [44]. This means that when a drug is prescribed off-label, an official assessment of effectiveness and safety for that purpose has not taken place. Off-label use of medication to treat diseases is common practice [44, 45] but it is not clear how often medication is prescribed off-label for enhancement purposes. In case of Modafinil, estimates are that $90 \%$ of pre- scriptions is off-label [46]. In other cases, the borderline between enhancement and therapeutic purposes may not be all that clear. For example, the prescription of propranolol for exam- or performanceanxiety is considered good medical practice in many countries but can also be seen as a form of enhancement.

An important moral concern regarding off-label use of enhancing drugs regards the health risks of such use in relation to effects - which are not always what they are expected to be. Professionals should assess this risk-benefit ratio of any drug they prescribe off-label, but potential users have their own responsibility as well. The model proposed by Synofzik elsewhere in this issue adequately describes how physicians should deal with off-label prescription [47].

One aspect that receives little attention in Synofzik's model concerns the moral responsibility of physicians for participating in certain enhancement practices. In a highly competitive society, social pressure or even coercion may occur to use drugs in order to live up to society's requirements. Are doctors 'complicit' if they support such a society by prescribing performance supporting drugs on demand? In the context of cosmetic surgery, Little has argued that doctors are complicit if they side "with the suspect norms of appearance"; norms that reflect or reinforce an unjust system of beliefs, attitudes and practices, such as racism and sexism [48]. While this kind of suspect norms may play a part in cosmetic surgery, this seems hardly the case in the context of psychopharmacology. While some may find society's emphasis on cognitive performance, 24/7 economic activity, or individual happiness undesirable, and resist the stimulation of these by way of psychopharmacology, it would be difficult to argue that these norms are unjust. However, some norms or practices might be undesirable for other reasons and it can be questioned to what degree doctors should become 'complicit' in these practices. For example, by prescribing modafinil for shift workers sleep disorder one could argue that doctors become 'complicit' in adapting workers to the demands of employers and society. Direct or indirect forms of coercion may take place if employers would require their employees to use enhancers [49]. Some professions, like those that require high concentration and carry heavy responsibilities like air traffic controllers, surgeons or military, 
may by more prone to such demands than others. This again raises the question of the role and responsibility of physicians who would prescribe such drugs offlabel. According to Glannon, "doctors may prescribe medication necessary for certain types of work" [2, p.114]. We believe, however, that more discussion is necessary before reaching any conclusions here.

These concerns regarding the responsibilities of doctors in prescribing off-label drugs for enhancement purposes have important implications for policy. First, more research into the safety and efficacy of off-label use is necessary, because currently there is a "gap in empirical research on off-label indications for psychotropic medications" [50]. According to a recent Dutch report there is a demand among physicians for more information about off-label prescription [45]. The same report notes that $22-45 \%$ of the physicians - depending on their specialism-are not aware when a prescription is off-label and that a considerable number of physicians do not inform or ask patients their consent. It is therefore, secondly, the task of professional medical organizations to raise awareness and increase knowledge regarding off-label practices in general, and to start the discussion regarding off-label use for enhancement purposes in particular.

A promising approach in order to gain insight in the use and safety of enhancers may be to find new ways of pharmacovigilance; "the process of evaluating and improving the safety of marketed medicines" [59]. In the current system, safety of off-label use of enhancers can only be assessed after they are being introduced to the market. The existing system, however, is criticized as having a limited effectiveness, limited stakeholder participation and a lack of transparency and legitimacy [57]. Moreover, it is questioned whether the existing model of pharmacovigilance can meet the challenges of $21^{\text {st }}$ century drug development, the increasing expectations of consumers and the benefits of new, more complex technologies [59]. New ways of pharmacovigilance may provide more opportunity for active stakeholder participation such as users of enhancers, health care professionals and the pharmaceutical industry and for communicating safety information with health care professionals, patients and consumers [58]. Consultation of consumer and patient organizations can be involved, as well as weblogs and Internet communities of people who experiment with such drugs.
Regulating Non-Prescription Use of Enhancers?

Considering the global market in pharmaceuticals it seems practically impossible to prevent the use of drugs with enhancing effects. Even when prescriptions or over the counter sales of certain drugs for enhancement purposes would be prohibited, people would still find ways to use them. Especially when enhancing medicines are at the same time registered for treatment of acknowledged medical conditions, it will be near impossible to prevent people from obtaining and using them. Online access is easy and many people will probably be interested in possibilities to enhance cognitive and other mental functions, as is the case with cosmetic surgery and sexual function. Right now, people are using drugs for their enhancing effects, but without any medical supervision or safety-checks.

Safety is an important issue in regulating drugs and one argument in favour of making enhancing drugs available though doctors or pharmacists is that this might prevent unsafe illegal practices. Many drugs purchased on the Internet are not of good quality, or may be counterfeit [51]. Another issue is that the information regarding these drugs is not very reliable; balanced information is hard to come by, so truly informed use is difficult. From the point of view of safety, it would be wise policy to find ways to make reliable information available for potential users, and to warn against false promises, and risky or unsafe practices. Such information should preferable be aimed at groups who are prone to abuse (e.g. students during examination time). The government should take responsibility to make sure potential users are informed of the realistic effects and risks of online 'smart drugs', for example by publishing a consumer alert for such drugs, as has been done, e.g. for at home genetic testing ${ }^{9}$. Such an alert should warn about inflated expectations and the risks of Internet purchases, give a realistic image of side effects, and advice to seek professional help or consultation in case of underlying psychological, social or physical problems.

\footnotetext{
${ }^{9}$ see for example the brochure with the appropriate title $A$ healthy dose of scepticism may be the best prescription, http:// www.ftc.gov/bcp/edu/pubs/consumer/health/hea02.shtm
} 


\section{Conclusions}

It is to be expected that in the near future new psychoactive medication will be developed that is primarily intended for specific disorders or diseases, but that can have enhancing effects on various mental functions in healthy people as well. These effects will probably be moderate, will enhance certain functions while impeding others, and may not work equally well for everyone. Still, the use of these psychoactive drugs is likely to expand beyond current medical indications. First, medical indications themselves are likely to expand, and so will prescriptions for conditions that we currently do not recognize as disorders. Second, off-label prescription of medication for explicit enhancement purposes is also likely to expand, as is the use of enhancing drugs without any prescription, e.g. purchased on the Internet.

Throughout this paper we have assumed that a general categorical prohibition of psychopharmacological enhancers is neither a desirable nor a realistic option. In the literature on cognitive enhancement that has accumulated over the last years, there are few, if any, authors who argue for a categorical prohibition of enhancing drugs. The ethical concerns that are raised here as well as in the literature contribute to finding responsible ways of dealing with these new developments [55].

As more or more powerful drugs with enhancing potential become available, there will be an increasing need for regulation of these drugs. Various regulatory options exist, ranging from off- or on-label prescription by doctors, to commercial prescriptions by cosmetic neurologists or schmocters, to over the counter sales. The discussion about changing or adapting existing regulations has already started [29, $30,47]$. Safety and efficacy are important considerations here, as is justice when it comes to the question of reimbursements. We have not answered (or dealt with) those issues here but wish to emphasize the importance of critical evaluation of the expected benefits and drawbacks of new enhancing drugs not only on an individual but also on a societal level. The important ethical question that remains open for further discussion is how concerns about the collective social consequences of enhancement should be taken into account and translated into policymaking. How can worries about collective effects such as resulting inequalities, normalization and exclusion of differences, or promotion of a 24/7 rat-race society be translated into policymaking with regard to enhancing drugs? How can collective benefits as well as side effects be assessed in our pluralistic liberal society, where opinions about the good life and the good society are so widely varied? These are questions that need to be on the ethical enhancement agenda.

Acknowledgments The research for this paper was funded by The Netherlands Organization for Scientific Research (NWO). The authors thank Prof. dr. Rein Vos and the participants of the Botox for the Brain workshop in Utrecht for their helpful comments on an earlier draft.

Open Access This article is distributed under the terms of the Creative Commons Attribution Noncommercial License which permits any noncommercial use, distribution, and reproduction in any medium, provided the original author(s) and source are credited.

\section{References}

1. Illes, J (ed). 2006. Neuroethics. Defining issues in theory, practice and policy. Oxford: Oxford University Press.

2. Glannon, W. 2007. Bioethics and the brain. Oxford: Oxford University Press.

3. Levy, N. 2007. Neuroethics. Challenges for the 21st century. Cambridge: Cambridge University Press.

4. Gazzaniga, M.S. 2005. The ethical brain. Washington DC: Dana Press.

5. Parens, E. 1998. Enhancing human traits: ethical and social implications. Washington DC: Georgetown University Press.

6. President's Council on Bioethics. 2003. Beyond therapy. Biotechnology and the pursuit of happiness. New York: Dana Press.

7. Buchanan, A., D.W. Brock, N. Daniels, and D. Wikler. 2000. From chance to choice. Genetics and justice. Cambridge: Cambridge University Press.

8. Harris, J. 2007. Enhancing Evolution. The ethical case for making better people. Princeton University Press.

9. Kramer, P.D. 2000. The Valorization of Sadness: Alienation and the Melancholic Temperament. Hastings Center Report 302: 13-18.

10. Elliott, C. 2000. Pursued by happiness and beaten senseless. Prozac and the American dream. Hastings Center Report 302: 7-12.

11. Diller, L.H. 1996. The run on Ritalin. Attention deficit disorder and stimulant treatment in the 1990's. Hastings Center Report 26: 12-18.

12. Rose, S. 2002. 'Smart drugs': do they work? Are they ethical? Will they be legal? Nature reviews neuroscience 3: 975-979.

13. Farah, M., J. Illes, et al. 2004. Neurocognitive enhancement: what can we do and what should we do? Nature reviews neuroscience 5: 421-425. 
14. Mehlman, M.J. 2004. Cognition-enhancing drugs. The Milbank Quarterly 823: 483-506.

15. Schermer, M. 2007. Brave New World versus Island. Utopian and dystopian views on psychopharmacology. Medicine, Health Care and Philosophy 102: 119-128.

16. Bostrom, N. 2003. Human genetic enhancements: a transhumanist perspective. Journal of Value Inquiry 374: 493506. See also www.transhumanism.org.

17. Savulescu, J. 2006. Justice, fairness, and enhancement. Annals of the New York Academy of Sciences 1093: 321338.

18. Fukuyama, F. 2002. Our posthuman future. Consequences of the biotechnology revolution. New York: Farrar, Strauss and Giroux.

19. Sandel, M.J. 2004. The case against perfection. Atlantic Monthly 293: 251-263.

20. Roco, M.C., and W.S. Bainbridge. 2002. Converging Technologies for Improving Human Performance. Arlington, Virginia: National Science Foundation.

21. Brown, N. 2003. Hope against hype - accountability in biopasts, presents and futures. Science Studies 162: 3-21.

22. Nordmann, A. 2007. If and Then: a Critique of Speculative NanoEthics. Nanoethics 11: 31-46.

23. Keulartz, J., M. Schermer, M. Korthals, and T. Swierstra. 2004. Ethics in a technological culture. A programmatic proposal for a pragmatist approach. Science, Technology and Human Values 291: 3-29.

24. de Jongh, R., I. Bolt, M. Schermer, and B. Olivier. 2008. Botox for the brain. Pharmacological enhancement of cognition, mood and personality traits. Neuroscience and Biobehavioral Reviews 324: 760-776.

25. Randall, D.C., N.L. Fleck, et al. 2004. The cognitiveenhancing properties of modafinil are limited in non-sleepdeprived middle-aged volunteers. Pharmacol Biochem Behav 77: 547-55.

26. Wesensten, N.J., and G. Belenky. 2002. Maintaining alertness and performance during sleep deprivation: modafinil versus caffeine. Psychopharmacology (Berl) 159: 238-247.

27. Elliott, R., B.J. Sahakian, et al. 1997. Effects of methylphenidate on spatial working memory and planning in healthy young adults. Psychopharmacology (Berl) 131: 196-206.

28. Juengst, E., R. Binstock, et al. 2003. Biogerontology, 'antiaging medicine', and the challenges of human enhancement. Hastings Center Report 33: 21-30.

29. Sahakian, B., and S. Morein-Zamir. 2007. Professor's little helper. Nature 450: 1157-1159.

30. Bostrom, N. 2008. Drugs can be used to treat more than diseases. Nature 451: 520.

31. Davis, K. 2007. Rethinking "Normal". The Hastings Center Report May-June: 44-47.

32. Moynihan, R., I. Heath, et al. 2002. Selling sickness: the pharmaceutical industry and disease mongering. British Medical Journal 324: 886-891.

33. Conrad, P. 2005. The Shifting Engines of Medicalization. Journal of Health and Social Behavior 46: 3-14.

34. Conrad, P., and D. Potter. 2000. From Hyperactive Children to ADHD Adults: Observations on the Expansion of Medical Categories. Social Problems 474: 559-582.

35. McCabe, S.E., C.J. Teter, and H. Wechsler. 2005. Nonmedical use of prescription stimulants among US college students: prevalence and correlates from a national survey. Addiction 100: 96-106.

36. Teter, C., S. McCabe, et al. 2006. Illicit use of specific prescription stimulants among college students: prevalence, motives, and routes of administration. Pharmacotherapy 26: 1501-1510.

37. Prudhomme White, B., K. Becker-Blease, and K. Grace Bishop. 2006. Stimulant medication use, misuse and abuse in an undergraduate and graduate student sample. Journal of American College Health 5: 261-8.

38. van der Poel, A., K. Lens, P. Vuijk, and R. Vet. 2007. Oneigenlijk gebruik van medicijnen door jongeren. [Abuse of medication by adolescents]. Rotterdam: Instituut voor VerslavingsOnderzoek.

39. http://www.nieuwsblad.be/Article/Detail.aspx?articleid= EK1CQJM5 (accessed 15 sept 2008)http://www.grenswe tenschap.nl/permalink.asp?grens $=1753$ (accessed 15 sept 2008)

40. Maher, B. 2008. Poll results: look who's doping. Nature 452: 674-5.

41. Schermer, M. 2008. On the argument that enhancement is cheating. Journal of Medical Ethics 34: 85-88.

42. Ravelingien, A., and A. Sandberg. 2008. Sleep better than medicine? Ethical issues related to 'wake enhancement'. Journal of Medical Ethics 349: e9.

43. Dehue, T. 2008. De depressie-epidemie. [The depression epidemic]. Amsterdam: Uitgeverij Augustus.

44. Dresser, R. 2007. The Curious Case of Off-Label Use. The Hastings Center Report May-June: 9-11.

45. Caspers, P.W.J., R. Gijsen, and A. Blokstra. 2007. Off-label gebruik van geneesmiddelen. Transparantiegewenst. (Offlabel use of precription drugs. Transparency required). Bilthoven: RIVM.

46. Vastag, B. 2004. Poised to challenge need for sleep, 'wakefullness enhancer' rouses concern. JAMA 291: 16770.

47. Synofzik, M. 2009. Ethically justified, clinically applicable criteria for physician-decision making in psychopharmacological enhancement. Neuroethics, this issue

48. Little, M.O. 1998. Cosmetic surgery, suspect norms and the ethics of complicity. In Enhancing Human Traits, ed. E. Parens, 162-176. Washington: Georgetown University Press.

49. Appel, J.M. 2008. When the boss turns pusher: a proposal for employee protections in the age of cosmetic neurology. Journal of Medical Ethics 34: 616-18.

50. Stein, D.J. 2008. Philosophy of psychopharmacology: a naturalist approach. Cambridge: Cambridge University Press.

51. Montoya, I.D., and E. Jano. 2007. Online pharmacies: safety and regulatory considerations. International Journal of Health Services 372: 279-289.

52. Savulescu, J. 2005. New breeds of humans: the moral obligation to enhance. Reproductive BioMedicine Online 10: $36-39$.

53. Riis, J., J.P. Simmons, and G.P. Goodwin. 2008. Preferences for enhancement pharmaceuticals: the reluctance to enhance fundamental traits. Journal of Consumer Research 35: 495-508.

54. Mehlman, M.J., and J.W. Berg. 2008. Human subject protections in biomedical enhancement research: assessing risk and benefit and obtaining informed consent. Journal of Law, Medicine and Ethics 36: 546-549. 
55. Greely, H., B. Sahakian, J. Harris, R.C. Kessler, M. Gazzaniga, P. Campbell, and N.J. Farah. 2008. Towards responsible use of cognitive-enhancing drugs by the healthy. Nature 456: 702-705.

56. Kirsch, I. et al. 2008. Initial severity and anti-depressant benefits: a meta-analysis of data submitted to the Food and Drug Administration. PloS Medicine 5: e45. doi:10.1371/ journal.pmed.0050045.

57. Fontanarosa, P.B., D. Rennie, and C.D. DeAngelis. 2004. Post-marketing Surveillance-Lack of Vigilance, Lack of Trust. JAMA 29221: 2647-2650.

58. Moors, E.H.M., W.P.C. Boon, R. Nahuis, and R.L.J. Vandeberg. 2008. User-producer interactions in emerging pharmaceutical and food innovations. International Journal of Innovation Management 123: 459-487.
59. Waller, P.C., and S.J.W. Evans. 2003. A model for the future conduct of pharmacovigilance. Pharmacoepidemiology and Drug Safety 12: 17-29.

60. Broersen, S., Ziekte te koop (Disease for sale). 2009. Medisch Contact 64: 20-22.

61. Wagena, E.J., and P. Knipschild. 2005. Do drug firms hoodwink medical journals? Or is something wrong with the contribution and integrity of declared authors. J Med Ethics 31: 307.

62. Sismondo, S. 2007. Ghost Management: How Much of the Medical Literature Is Shaped Behind the Scenes by the Pharmaceutical Industry? PLoS Medicine 4: 1429-1433.

63. Moffatt, B., and C. Elliott. 2007. Ghost Marketing; pharmaceutical companies and ghostwritten journal articles. Perspectives in Biology and Medicine 50: 18-31. 